Thorax (1976), 31, 527.

\title{
Evolution of disability in coalworkers' pneumoconiosis
}

\author{
J. P. LYONS and H. CAMPBELL \\ Pneumoconiosis Medical Panel, 9 The Friary, Cardiff; Department of Medical Statistics, \\ Welsh National School of Medicine, Cardiff
}

\begin{abstract}
Lyons, J. P. and Campbell, H. (1976). Thorax, 31, 527-533. Evolution of disability in coalworkers' pneumoconiosis. Retrospective analysis of the results of serial ventilatory capacity tests $\left(\mathrm{FEV}_{1 \cdot 0}\right)$, which had extended over an average period of almost 15 years, has been carried out in $\mathbf{2 1 5}$ miners and ex-miners who suffer with coalworkers' pneumoconiosis. All were unselected previously diagnosed cases who attend the Cardiff Pneumoconiosis Panel at regular intervals for re-assessment examinations. They consisted of 68 miners and 147 ex-miners and they were divided into three groups according to their radiological category at their most recent examination, carried out in either 1973 or 1974. There were 90 cases of category B progressive massive fibrosis (PMF), 50 cases of category A PMF and 75 cases of simple pneumoconiosis. Findings for the 38 life-long non-smokers within the $\mathbf{2 1 5}$ were compared with those for the smokers.

All three groups showed progressive impairment of ventilation over the whole period of observation. This was most marked in the category B cases but this group had already acquired a substantial proportion of their eventual impairment while still classified radiologically as category $\mathrm{A}$ or as simple pneumoconiosis. These findings are not compatible with the view that coalworkers' pneumoconiosis does not cause significant impairment of ventilation until the category $B$ radiological stage is attained; they suggest rather that cases destined to progress to serious disablement show evidence of progressive impairment of ventilation at very much earlier radiological stages. Non-smokers showed a pattern of impairment similar to that of the smokers but were less disabled; the differences, however, were slight and not statistically significant.
\end{abstract}

There is general agreement among writers on the subject that coalworkers' pneumoconiosis can be a cause of substantial respiratory disability and premature death in its later stages, when the radiological assessment has reached at least category ' $B$ ' progressive massive fibrosis; but whether this disease can cause significant disablement at earlier radiological stages than this is still open to question. Evidence from the Pneumoconiosis Research Unit of the Medical Research Council, Gilson and Hugh Jones (1955), Carpenter et al. (1956), and Cochrane, Moore, and Thomas (1961) indicated that simple pneumoconiosis per se was probably not a cause of significant disability, and Cochrane (1973) suggested that simple pneumoconiosis together with early category ' $A$ ' progressive massive fibrosis caused neither premature death nor significant respiratory disability.
In contrast, Rogan et al. (1961), Ashford et al. (1968), and Morgan et al. (1971) found evidence of disturbance of lung function which was related to the radiological category in simple pneumoconiosis, and Lyons et al. (1972) found evidence of progressive impairment of ventilatory capacity at all radiological stages of the disease which was related to emphysema but not to the radiological category of simple pneumoconiosis. Many of the aforementioned studies were carried out on working miners, thereby excluding the more disabled and elderly ex-miners, and most of them were concerned with a single aspect of lung function tested at one point in time only. In a chronic progressive disease like coalworkers' pneumoconiosis, one might expect that serial tests carried out on the same individuals would be of more value. Serial tests of respiratory function were, in fact, included in the study of Lyons et al. (1972) and 
also in an earlier study by Higgins and Oldham (1962), but in both of these the period of observation was probably too small (amounting to not more than five years) for the results to be very conclusive.

Obviously longer periods of observation should prove more revealing concerning the evolution of disability in the disease, and since serial tests of ventilatory capacity have now been in continuous use at the Cardiff Pneumoconiosis Panel since 1957 , it was thought that a retrospective study of lung function in miners examined routinely at the Panel might throw some light on the evolution of disablement in them. Cases who had reached the stage of PMF at the time of the latest examination would, it was thought, prove particularly interesting, since if disablement is present in such cases it is generally attributable to the disease; and a retrospective assessment of lung function studies in them should help to throw some light on the behaviour of the disease in its early stages. Such a study should indicate whether or not pulmonary disablement was present at the time of the earlier radiological categories in those cases showing disablement at the category B stage.

\section{MATERIAI}

The material consists of 215 unselected cases of coalworkers' pneumoconiosis, all of whom had been diagnosed previously and accepted for compensation by the Cardiff Pneumoconiosis Panel. Such cases normally should have radiographic changes amounting to at least category 2 of the ILO Radiological Classification of Pneumoconiosis. All diagnosed cases of coalworkers' pneumoconiosis are regularly re-examined by the Panel; those cases who show radiographic evidence of PMF are normally re-examined at two-year intervals irrespective of whether or not pulmonary disablement is present, while cases of simple pneumoconiosis are re-examined every three years. For the purpose of the present investigation all such cases, with certain exceptions to be enumerated later, who attended during specific periods of 1973 and 1974 were included, and most of these had had serial tests of lung function over comparatively long periods. In a previous paper (Ryder et al., 1970), we indicated why, in our view, because of the activities of the NCB Radiological Service, most cases of pneumoconiosis eligible for compensation should be known to the Panel, and these reasons apply even more forcibly to men with progressive massive fibrosis. Hence we believe that such a sample should be reasonably representative of those categories of pneumoconiosis in the coal-mining community as a whole in South Wales since it seems most un $\vec{\sigma}_{\bar{\sigma}}$ likely that a substantial number of potentiallye diagnosable cases could be unknown to the Panef at the present time.

The majority of the PMF cases were collected between June and October 1973, and all of the

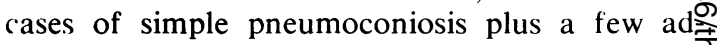
ditional PMF cases were collected between Ma $\vec{x}$ and August 1974. The exceptions were as follows $\omega^{\omega}$

(a) cases who were considered to be category Br radiologically over the entire period of physiologi cal observation, that is, category $\mathbf{B}$ before the time of the first pulmonary function test. Suclp cases are recognized to suffer with progressive disablement, and no purpose relevant to the cure rent investigation would be served by including them;

(b) cases who were too ill to attend at the Panet and were thus seen at home for their routings examinations were also excluded since recent comparable ventilatory capacity findings were not available for them;

(c) cases who had attended the Panel for les than six years as it was considered that the perio\& of physiological and radiological observation was too short.

It is recognized that this method of collectio produces a bias in favour of less severely disabled cases and early category B cases, but this would. tend to negate any suggestion that the Panel cases might be biased in the opposite direction. The coal-mining population in South Wales is notably stable one and so it is unlikely that an significant movement of population has take place over the period of observation, and death? due to the disease will presumably have occurre mainly among the more advanced cases whe would not have been eligible for the survey on the account.

\section{METHOD}

In all the eligible cases seen during 1973 and 1974 , there were available a current radiograpt and a pulmonary function test; the earliest Pnew moconiosis Medical Panel examination to include a lung function test was then identified and the radiograph contemporary with the first lung funco tion test was selected. In most cases the interva between the first and latest $\mathrm{FEV}_{1 \cdot 0}$ ranged from 10 to 17 years and the average period of observa tion was 14 years. In cases who were considerefo to be category B at the most recent 1973/74 exant 
ination, all the radiographs taken during the intervening period were examined and an intermediate film which corresponded as closely as possible with the transitional category $A$ to category B radiological stage was selected together with its concurrent ventilatory finding. Such cases might reasonably be interpreted radiologically as category A/B and were so termed for the purpose of the investigation. In addition, in the 75 cases of simple pneumoconiosis, the $\mathrm{FEV}_{1.0}$ approximately midway in time between the first and final was also recorded. The ventilatory capacity tests were carried out in standardized conditions using the Poulton spirometer, virtually all of them by the same highly experienced technician.

All the radiographs were re-read jointly at the same time especiallly for this study by JPL and WC according to the ILO 1968 classification, but for the purpose of the paper the numerical category only has been used. It should be made clear that in many cases the film taken at the same time as the first FEV and used in this paper post-dated, sometimes by several years, the film taken when the disease was first diagnosed. Thus some cases who had earlier been diagnosed as showing category 2 changes by the Panel could be adjudged as showing only category 1 changes by the present readers on the later (first FEV) film. In a few cases where this occurred it was due to a tendency to 'overread' earlier films at a time when the ILO radiological classification was in its formative stages, but in others actual regression was adjudged to have taken place. There were 38 lifelong non-smokers within the 215 cases. The ventilatory findings for these were compared with those of the 177 smokers.

\section{RESULTS}

There were 215 cases in the study, 75 who were graded as simple pneumoconiosis (in 1973/74), 50 as category $\mathrm{A}$, and 90 as category $\mathrm{B}$. One hundred and forty seven of the men $(68 \%)$ were retired from coal mining and $68(32 \%)$ were still employed in the industry. Those miners who were continuing to work in the industry either underground or on the surface were in dust free or dust 'approved' conditions, since all were recognized as cases of pneumoconiosis. The ex-miners were mainly men who had retired because of age or disease but included men who had left the industry while still of working age and were employed elsewhere. The average duration of follow-up since the first pulmonary function test was $14 \cdot 8$ years for all cases, 14.8 for the simple pneumoconiosis, 14.9 for category $A$, and 14.7 for category B.

Table I shows the average age and average duration of exposure to dust underground for each of the radiological categories. The average age of the 215 miners was 60 years and the exposure to dust underground 36 years. Although the cases with simple pneumoconiosis were two years younger on average and had three years' shorter duration of exposure to dust, these differences were not statistically significant.

T A B L E I

MINERS AND EX-MINERS: RADIOLOGICAL CATEGORY OF PNEUMOCONIOSIS IN 1973/74, MEAN AGE, AND MEAN OF PNEUMOCONIOSIS IN 1973/74, MEAN AGE, AND MEAN

\begin{tabular}{|c|c|c|c|c|}
\hline \multirow{2}{*}{ Category } & \multicolumn{2}{|c|}{ Number } & \multirow{2}{*}{$\underset{(y r)}{\text { Mean Age }}$} & \multirow{2}{*}{$\underset{\text { (yr) }}{\text { Mean }}$} \\
\hline & Total & Ex-miners & & \\
\hline $\begin{array}{l}\text { A } \\
\text { Simple }\end{array}$ & $\begin{array}{l}50 \\
90 \\
75\end{array}$ & $\begin{array}{ll}38 & 76 \% \\
65 & 72 \% \\
44 & 59 \%\end{array}$ & $\begin{array}{l}62 \\
60 \\
58\end{array}$ & $\begin{array}{l}37 \\
37 \\
33\end{array}$ \\
\hline
\end{tabular}

Table II shows the numerical radiological category in $1973 / 74$ and at the time of the first pulmonary function test for the three groups. There were by definition no men who progressed from

T A B L E I I

PROGRESSION OF CASES OF COALWORKERS PNEUMOCONIOSIS: RADIOLOGICAL CATEGORY AT TIME OF FIRST AND MOST RECENT PULMONARY FUNCTION TESTS

\begin{tabular}{|c|c|c|c|c|c|c|}
\hline \multirow{2}{*}{$\begin{array}{c}\text { Radiological } \\
\text { Category }\end{array}$} & \multicolumn{2}{|c|}{ Simple Cases } & \multicolumn{2}{|c|}{ Category A } & \multicolumn{2}{|c|}{ Category B } \\
\hline & First & Recent & First & Recent & First & Recent \\
\hline $0 / 1$ & 7 & 5 & - & - & 1 & - \\
\hline $\begin{array}{l}1 / 0 \\
1 / 1 \\
1 / 2\end{array}$ & $\begin{array}{r}4 \\
28 \\
8\end{array}$ & $\begin{array}{r}2 \\
25 \\
13\end{array}$ & $\begin{array}{l}3 \\
3 \\
5\end{array}$ & $\overline{-}$ & $\begin{array}{l}1 \\
3 \\
1\end{array}$ & 二 \\
\hline $\begin{array}{l}2 / 1 \\
2 / 2 \\
2 / 3\end{array}$ & $\begin{array}{r}15 \\
11 \\
2\end{array}$ & $\begin{array}{r}15 \\
11 \\
2\end{array}$ & $\begin{array}{l}8 \\
4 \\
3\end{array}$ & 二 & $\begin{array}{r}3 \\
10 \\
6\end{array}$ & 二 \\
\hline $3 / 2$ & - & 2 & 1 & - & 3 & - \\
\hline $\begin{array}{l}\text { 0/A } \\
\text { 1/A } \\
\text { 2/A } \\
\text { 3/A } \\
\text { NR/A }\end{array}$ & $\begin{array}{l}\overline{ } \\
\bar{z}\end{array}$ & $\begin{array}{l}\overline{ } \\
\bar{E}\end{array}$ & $\begin{array}{l}2 \\
8 \\
9 \\
2 \\
2\end{array}$ & $\begin{array}{r}6 \\
17 \\
21 \\
6\end{array}$ & $\begin{array}{r}3 \\
17 \\
30 \\
10 \\
2\end{array}$ & $\begin{array}{l}\overline{ } \\
\bar{z}\end{array}$ \\
\hline $\begin{array}{l}0 / \mathrm{B} \\
1 / \mathrm{B} \\
2 / \mathrm{B} \\
3 / \mathrm{B} \\
\mathrm{NR} / \mathrm{B}\end{array}$ & $\begin{array}{l}\overline{ } \\
\bar{z}\end{array}$ & $\begin{array}{l}\overline{ } \\
\bar{z}\end{array}$ & $\begin{array}{l}= \\
\bar{z}\end{array}$ & $\begin{array}{l}= \\
=\end{array}$ & $\begin{array}{l}\bar{z} \\
\bar{z}\end{array}$ & $\begin{array}{l}15 \\
34 \\
27 \\
1 \\
13\end{array}$ \\
\hline & 75 & 75 & 50 & 50 & 90 & 90 \\
\hline
\end{tabular}

Note: NR/A = category A of PMF. Simple pneumoconiosis grading not read. 
simple pneumoconiosis to PMF in the first group; 27 out of the 50 men $(54 \%)$ had progressed from simple pneumoconiosis to category $A$ in the second group, 28 men $(31 \%)$ had progressed from simple pneumoconiosis to category $B$, and 62 men $(69 \%)$ had progressed from category $A$ to category $B$ in the third group. There were no regressions in PMF categories.

In the reading of the category of simple pneumoconiosis there were, however, considerable changes both upwards and downwards. Of the 75 cases of simple pneumoconiosis, $51(68 \%)$ remained in the same broad category, $16(21 \%)$ advanced one broad category, and eight $(11 \%)$ showed regression of one category. Among the 50 cases of category A there were seven cases $(14 \%)$ in whom the background of simple pneumoconiosis was not read, five cases $(10 \%)$ showed progression of the simple pneumoconiosis, and 14 $(28 \%)$ showed regression, $24(48 \%)$ remaining constant. Among the 90 cases of category B, there were $13(14 \%)$ in which the background of simple pneumoconiosis was not read, there were only 5 cases $(6 \%)$ of progression, and 39 cases $(43 \%)$ of regression, 33 cases $(37 \%)$ remaining constant.

Radiological regression of simple category of pneumoconiosis is well recognized as occurring in cases with PMF where it is usually attributed to progressing emphysema and fibrosis. It is not so widely recognized that similar regression can occur in cases of simple pneumoconiosis, but it seems that it does occur and is probably brought about by the same processes. In the present cases it is acknowledged that differences in film quality and of radiological technique may have contributed to apparent lack of progression and regression, but the films were on the whole quite comparable, the bulk of them having been taken within the Panel, and the present readers are satisfied that actual radiological regression had taken place in some cases, notably in terms nodulation.

It seems likely that in miners who have lefe significant dust exposure, pathological sequela $\overline{8}$ may continue to develop without further cos related radiological progression of the classical simple nodular variety. We described and reporte $\Phi$ some evidence to this effect (Lyons et al., 1974) in a group of deceased miners, some of whom had also shown radiological regression during life. $\overrightarrow{\vec{*}}$

The primary purpose of this study, however, to demonstrate the degree and the progression of pulmonary disability by men suffering from thy disease. Pulmonary disability has been measure by the deficit in $\mathrm{FEV}_{1.0}$ adjusted for age and height according to Cotes' (1968) formula within each radiological category. These expected values equate fairly well with those determined and usea by Carpenter et al. (1956) in their Rhondda Fach study of non-miners aged between 50 and 65, ins cluding those with respiratory symptoms who are good controls for our miners of similar age, mano of whom actually reside in the Rhondda Fach The average $\mathrm{FEV}_{1.0}$ of that non-mining populas tion was approximately 0.21 lower than that of our cases but the annual fall in $\mathrm{FEV}_{1.0}$ for the non-miners was virtually identical with Cotes predicted average figure of approximately 0.034 per annum.

Table III shows the average deficit for each group of patients at the recent examination if $1973 / 74$, at the intermediate examination, and at the first pulmonary function test which was of average 14.8 years previously. This deficit is als illustrated by the Figure.

All groups of pneumoconiotics show a progres sive pulmonary disability both at the recent ex amination and at all the previous examinations The cases of simple pneumoconiosis and of cateo gory $A$ behave in a similar way with a defici greater than their expected value for age of apo

T A B L E I I I

PROGRESSION IN CASES OF COAL WORKERS' PNEUMOCONIOSIS: DEFICIT OF FEV 1.0 ADJUSTED FOR CHANGING AGE: MEAN VALUE \pm STANDARD ERROR OF MEAN

\begin{tabular}{|c|c|c|c|c|c|c|}
\hline \multirow{2}{*}{$\begin{array}{c}\text { Current } \\
\text { Radiographic } \\
\text { Status }\end{array}$} & \multirow{2}{*}{$\underset{\text { Men }}{\text { Number of }}$} & \multicolumn{2}{|c|}{ Initial FEV } & \multicolumn{2}{|c|}{ Intermediate FEV } & \multirow{2}{*}{$\frac{\text { Recent FEV }}{\text { Deficit (1/ses) }}$} \\
\hline & & $\begin{array}{c}\text { Years } \\
\text { Before }\end{array}$ & Deficit $(1 / \mathrm{sec})$ & $\begin{array}{c}\text { Years } \\
\text { Before }\end{array}$ & Deficit $(1 / \mathrm{sec})$ & \\
\hline $\begin{array}{l}\text { Simple } \\
\text { Category A } \\
\text { Category B }\end{array}$ & $\begin{array}{l}75 \\
50 \\
90\end{array}$ & $\begin{array}{l}14 \cdot 8 \\
14 \cdot 9 \\
14 \cdot 7\end{array}$ & $\begin{array}{l}0.42 \pm 0.06 \\
0.43 \pm 0.06 \\
0.52 \pm 0.04\end{array}$ & $\begin{array}{l}7 \cdot 2 \\
\mathrm{NK} \\
7 \cdot 5\end{array}$ & $\begin{array}{l}0.47 \pm 0.07 \\
\text { NK } \\
0.65 \pm 0.05\end{array}$ & $\begin{array}{l}0.62 \pm 0.08 \\
0.55 \pm 0.09 \\
0.87 \pm 0.06\end{array}$ \\
\hline
\end{tabular}

All deficits are statistically significant $\mathbf{P}<0.001$. 


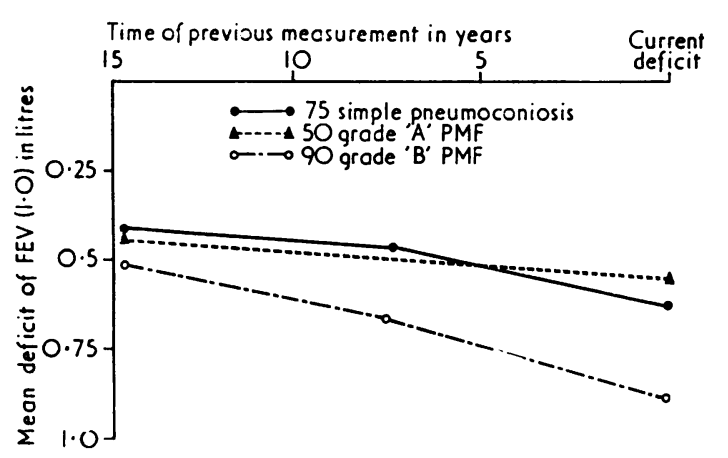

FIGURE. Mean deficit of $F E V_{1 \cdot 0}$ for the three patient groups.

proximately $600 \mathrm{ml}$ at the recent examinations and of approximately $420 \mathrm{ml}$ at the first examination 14 or 15 years previously. In this interval of time the men will also, of course, have lost on average $500 \mathrm{ml}$ due to advancing age, and hence $600 \mathrm{ml}$ deficit at the age of 60 is a greater disabilty than $420 \mathrm{ml}$ was at the age of 45 . In these cases the increase in pulmonary disability had been slow and would be hardly perceptible over a period of five years.

In the group of men destined to reach category B their recent pulmonary deficit (mean: $870 \mathrm{ml}$ ) was greater than was that of the other two groups. Fifteen years earlier these men already had a deficit of $520 \mathrm{ml}$ which was more severe than that of the other two groups. At the intermediate stage, after seven years when their radiological category was A/B their deficit had increased to $650 \mathrm{ml}$, which was similar to the deficit of the other groups after 14 or 15 years. Thus this increasing deficit in pulmonary capacity was progressive during the whole of the period under study. It was not a step function with rapid deterioration at the onset of category $\mathbf{B}$.

The average annual increase in the rate of fall of FEV $_{1.0}$ over that expected is shown in Table IV. Comparison with Table III will indicate that in the category $B$ and the simple cases (category A cases were not determined) the rate of fall is increasing with the passing of time, presumably due to progression of disease or advancing years or more probably a combination of both. These findings are consistent with a very slowly progressive chronic fibrotic respiratory disease, and it seems probable that disablement may not achieve significant proportions until the sixth decade, or later in many cases, a point of practical significance today because of increased life expectancy.
T A B L E I V

DISABILITY IN COAL WORKERS' PNEUMOCONIOSIS: ANNUAL INCREASE IN DEFICIT IN FEV 1.0

\begin{tabular}{c|c|c}
\hline $\begin{array}{c}\text { Category of } \\
\text { Pneumoconiosis }\end{array}$ & Follow-up & $\begin{array}{c}\text { Annual Increase in } \\
\text { Deficit above Expected } \\
\text { Deficit due to Ageing }\end{array}$ \\
\hline Simple & 14.8 years & $14 \mathrm{ml}$ \\
Category A & 14.9 years & $\begin{array}{r}8 \mathrm{ml} \\
\text { Category B }\end{array}$ \\
\hline
\end{tabular}

The differential findings for ventilatory impairment in cigarette smokers and non-smokers are set out in Table V. All the groups had a deficit in FEV $_{1 \cdot 0}$ greater than the expected value, and this deficit increased over the 14-year period of observation. The deficit was greater in the smokers than the non-smokers in all except the small group of eight category A cases when considered on their own rather than in combination with the 14 simple cases when the uniformity is restored. None of the differences, however, between smokers and non-smokers is statistically significant $(t<2 \cdot 0$; $P>0.05)$. In comparing the ventilatory findings of cigarette smokers and life-long non-smokers, it must be kept in mind that the expected values of the latter may be up to a litre more than that of the smokers (Wilson et al., 1960). Insofar as the present cases are concerned, since the largest difference between the groups at any point is 0.461 , and usually considerably less, it seems reasonable to assume that there is impairment of ventilatory capacity in all of the cases which is not due to the effects of smoking, and which is probably affecting both smokers and non-smokers in equal measure, the most probable cause of this being pneumoconiosis.

\section{DISCUSSION}

It might be argued that at least some of the ventilatory impairment in our cases may have been due to dust-induced disease other than pneumoconiosis, notably chronic bronchitis, but we are unaware of any conclusive evidence to this effect. The Special Committee of the Medical Research Council (1966) set up to investigate this matter was unable to find that intensity of dust exposure was a significant factor in determining the prevalence of chronic bronchitis in coalworkers. Rogan et al. (1973) found an association between increasing dust exposure and ventilatory impairment without radiological evidence of pneumoconiosis. but this does not mean that the earlier 
T A B L E V

DISABILITY IN COAL WORKERS' PNEUMOCONIOSIS: SMOKERS AND NON-SMOKERS: DEFICIT IN FEV $1 \cdot 0$ (1/sec)

\begin{tabular}{|c|c|c|c|c|c|c|}
\hline \multirow{2}{*}{$\begin{array}{c}\text { Category of } \\
\text { Pneumoconiosis }\end{array}$} & \multicolumn{3}{|c|}{ Initial Deficit } & \multicolumn{3}{|c|}{ Recent Deficit } \\
\hline & Smokers & Non-smokers & All & Smokers & Non-smokers & All \\
\hline $\begin{array}{l}\text { Simple } \\
\text { PMF (A) } \\
\text { Simple + PMF (A) } \\
\text { PMF (B) }\end{array}$ & $\begin{array}{lr}0.48 & (61) \\
0.39 & (42) \\
0.45 & (103) \\
0.54 & (74)\end{array}$ & $\begin{array}{ll}0.12 & (14) \\
0.61 & (8) \\
0.31 & (22) \\
0.41 & (16)\end{array}$ & $\begin{array}{l}0.42 \\
0.43 \\
0.42 \\
0.52\end{array}$ & $\begin{array}{l}0.71 \\
0.51 \\
0.63 \\
0.92\end{array}$ & $\begin{array}{l}0.25 \\
0.74 \\
0.43 \\
0.66\end{array}$ & $\begin{array}{l}0.63 \\
0.55 \\
0.59 \\
0.87\end{array}$ \\
\hline
\end{tabular}

Non-smokers $=$ never smoked more than one cigarette per day for one year.

Number of cases in brackets.

pathological changes of pneumoconiosis were not already present.

Many authors have described finding established simple pneumoconiosis at necropsy in so-called category $O$ cases. Lyons et al. (1972; 1974), Naeye (1972), Heitzman et al. (1972), and Gough, James, and Wentworth (1949) maintained that widespread focal emphysema may have no radiological counterpart. It seems quite conceivable, therefore, that some degree of impairment of ventilatory capacity due to pneumoconiosis may be present in some cases before significant radiological changes are manifest. Such would be quite consistent with our present findings as the Figure might suggest. The degree of ventilatory impairment present in the cases at the beginning of the period of observation coupled with the subsequent abnormal annual fall of $\mathrm{FEV}_{1 \cdot 0}$ indicates that the impairment in some must have begun considerably earlier than the time of the first FEV and presumably at a much earlier radiological stage, possibly even a pre-radiological stage.

It is difficult to reconcile the ventilatory findings in these category $B$ cases with the view that neither the simple nor the category A stages of coalworkers' pneumoconiosis cause respiratory disability while accepting that the category $B$ stage does. Our evidence suggests that cases destined to progress to category B show evidence of it long before that category is reached, and we believe that retrospective assessment of existing category B cases will, in general, show this to be the case if serial physiological observations are carried out. Only one case with a normal FEV at the $A / B$ stage exhibited the average deficit of 0.84 or more at the category B stage.

The separate groups of category A and simple pneumoconiosis cases are less disabled than the category B cases, despite approximately similar dust exposure and age groups. They are presumably less susceptible to the effects of dust for constitutional and other reasons which may not be apparent. It seems reasonable to conclude, neverf theless, having regard to the reduced average ven-o tilatory findings and the increasing fall in FEV per annum, that a proportion of cases must be significantly disabled on an individual basis, anc also that some cases may not show significan? disablement until comparatively late in life. Or? the other hand, it seems that an increased rate of fall of FEV starts at an early stage of the disease, and it may be that serial observations of ventilatory capacity might prove more valuable than radiology in the early detection of susceptible cases.

We are indebted to Dr. James Carmichael, Chie? Medical Adviser to the Department of Health and Social Security, for permission to publish and to use the Panel material; to Mr. W. G. Clarke, MBE, for assistance in reading the radiographs; and to Miss $C_{\text {. }}$. Squance, Cardiff Pneumoconiosis Medical Panel, for secretarial assistance.

\section{REFERENCES}

Ashford, J. R., Brown, S., Morgan, D. C., and Rae S. (1968). The pulmonary ventilatory function of coal miners in the United Kingdom. Americar Review of Respiratory Diseases, 97, 810.

Carpenter, R. G., Cochrane, A. L., Gilson, J. C., and Higgins, I. T. T. (1956). The relationship bee tween ventilatory capacity and simple pneumo coniosis in coalworkers. British Journal of Indus कै trial Medicine, 13, 166.

Cotes, J. E. (1968). Lung Function, 2nd edition p. 377. Blackwell Scientific Publications, Oxfordw

Cochrane, A. L. (1973). Relation between radio graphic categories of coalworkers' pneumeo coniosis and expectation of life. British Medicat Journal, 2, 532.

Cochrane, A. L., Moore, F., and Thomas, J. (1961) The prognostic value of radiological classification in cases of progressive massive fibrosis. Tubercle 42, 64.

Gilson, J. C. and Hugh Jones (1955). Lung functio疋 in coalworkers' pneumoconiosis. Medical Reo search Council Special Report Series, 290. 
Gough, J., James, W. R. L., and Wentworth, J. E. (1949). A comparison of the radiological and pathological changes in coalworkers' pneumoconiosis. Journal of the Faculty of Radiologists, 1, 28-39.

Heitzman, E. R., Naeye, R. L., and Markarian, B. (1972). Roentgen pathological correlations in coalworkers' pneumoconiosis. Annals of the New York Academy of Sciences, 200, 510.

Higgins, I. T. T. and Oldham, P. D. (1962). Ventilatory capacity in miners. British Journal of Industrial Medicine, 19, 65.

Lyons, J. P., Ryder, R. C., Campbell, H., Clarke, W. G., and Gough, J. (1974). Significance of irregular opacities in the radiology of coalworkers' pneumoconiosis. British Journal of Industrial Medicine, 31, 36.

Lyons, J. P., Ryder, R., Campbell, H., and Gough, J. (1972). Pulmonary disability in coalworkers' pneumoconiosis. British Medical Journal, 1, 713.

Morgan, W. K. C., Burgess, D. B., Lapp, N. L., and Seaton, A. (1971). Hyperinflation of the lungs in coal miners. Thorax, 26, 585.

Naeye, R. L. (1972). Types of fibrosis in coalworkers' pneumoconiosis. Annals of the New York Academy of Sciences, 200, 381.
Rogan, J. M., Ashford, J. R., Chapman, P. J., Duffield, D. P.. Fay, J. W. J., and Rae. S. (1961). Pneumoconiosis and respiratory symptoms in miners at eight collieries. British Medical Journal, $1,1337$.

Rogan, J. M., Attfield, M. D., Jacobsen, M.. Rae, S., Walker, D. D., and Walton, W. H. (1973). Role of dust in the working environment in development of chronic bronchitis in British coal miners. British Journal of Industrial Medicine, 30, 217.

Ryder, R., Lyons, J. P., Campbell, H., and Gough, J. (1970). Emphysema in coal workers' pneumoconiosis. British Medical Journal, 3, 481.

Wilson, R. H., Meador, R. S., Jay, B. E., and Higgins, E. (1960). The pulmonary pathologic physiology of persons who smoke cigarettes. New England Journal of Medicine, 262, 956.

Requests for reprints to: Dr. J. P. Lyons, Pneumcconiosis Medical Panel, Prudential Building, 9 The Friary, Cardiff. 